\title{
Delphi-Based Consensus on Treatment Intensification in Type 2 Diabetes Subjects Failing Basal Insulin Supported Oral Treatment: Focus on Basal Insulin + GLP-1 Receptor Agonist Combination Therapies
}

\author{
Gian Paolo Fadini (D) Olga Disoteo · Riccardo Candido • \\ Paolo Di Bartolo $\cdot$ Luigi Laviola $\cdot$ Agostino Consoli
}

Received: December 18, 2020 / Accepted: January 23, 2021 / Published online: February 7, 2021

(c) The Author(s) 2021

\section{ABSTRACT}

Introduction: The aim of this study was to elaborate a consensus on treatment intensification strategies in patients with type 2 diabetes failing basal insulin supported oral therapy (BOT). The panel focused on glucagon-like peptide-1 receptor agonists (GLP-1RA) and basal insulin (BI) combinations.

\section{G. P. Fadini $(\bowtie)$}

Division of Metabolic Diseases, Department of Medicine, University of Padova, Padua, Italy

e-mail: gianpaolo.fadini@unipd.it

O. Disoteo

Diabetes Unit, SSD Diabetologia, ASST Grande

Ospedale Metropolitano Niguarda, Milan, Italy

R. Candido

Diabetes Center District 3, Azienda Sanitaria

Universitaria Giuliano Isontina, Trieste, Italy

P. Di Bartolo

Ravenna Diabetes Clinic, Romagna Local Health

Authority, Ravenna, Italy

L. Laviola

Section of Internal Medicine, Endocrinology,

Andrology and Metabolic Diseases, Department of

Emergency and Transplants, University of Bari Aldo

Moro, Bari, Italy

A. Consoli

Department of Medicine and Aging Sciences (DMSI)

and Center for Research on Ageing and

Translational Medicine (CeSI-Met), University of

Chieti, Chieti, Italy
Methods: The authors developed a Delphi questionnaire organized into ten statements and 77 items that focused on: the definition of BOT and BOT failure, intensification strategies, fixed-dose combinations in general and the BI/ GLP-1RA fixed combination. The survey was administered in two rounds to a panel of 80 Italian diabetes specialists, who rated their level of agreement with each item on a 5-point Likert scale. Consensus was predefined as $>66 \%$ of the panel agreeing/disagreeing on any given item.

Results: Consensus was achieved for 71 of the 77 items. The panel agreed that the use of sulfonylureas in the BOT regimen is inappropriate. BOT failure was defined as individualized targets not being met for glycated hemoglobin, fasting plasma glucose and/or postprandial plasma glucose. There was agreement that postprandial hyperglycaemia and/or presence of nocturnal hypoglycaemia or weight gain define BOT failure. Addition of a GLP-1RA to BI therapy was considered to be the best option for BOT intensification. There was consensus for the use of BI/GLP-1RA fixed combinations as valuable options to increase compliance and safely improve glycaemic control. The panel agreed in considering the fixed-ratio combination insulin degludec/liraglutide (IDegLira) to be preferable to the fixed-ratio combination insulin glargine/lixisenatide (iGlarLixi) in the control of glycaemia, body weight and cardiovascular risk. 
Conclusion: According to this Delphi consensus, the addition of a GLP-1RA may be the best option to intensify BOT. The BI/GLP-1RA fixed combinations may increase compliance and optimize the advantages of each of these molecules.

Keywords: Basalinsulin + GLP-1RA combination therapies; Basal oral therapy; Delphi method; Expert consensus; Insulin intensification; Type 2 diabetes

\section{Key Summary Points}

Why carry out this study?

Glycaemic control is suboptimal in a large proportion of patients with type 2 diabetes (T2D), including those who have started insulin treatment, possibly due to clinical inertia in basal insulin uptitration and/or intensification.

The aim of this study was to elaborate a consensus on treatment intensification strategies in patients with T2D failing basal supported-oral therapy (BOT), focusing on the use of fixed combinations of basal insulin and glucagon-like peptide1 receptor agonists (BI/GLP-1RA).

\section{What was learned from the study?}

The use of sulfonylureas in the BOT regimen is considered inappropriate.

BOT failure was defined as individualized targets not being met for glycated haemoglobin, fasting plasma glucose and/ or postprandial glucose. Postprandial hyperglycaemia and/or presence of nocturnal hypoglycaemia or weight gain were also aspects contributing to BOT failure.

The fixed-ratio combination insulin degludec/liraglutide (IDegLira) was considered preferable to the fixed-ratio combination insulin glargine/lixisenatide (iGlarLixi) in the control of glycaemia, body weight and cardiovascular risk.
Addition of a GLP-1RA may be the best option to intensify BOT. The BI/GLP-1RA fixed combinations may increase compliance and optimize the advantages of using these molecules together.

\section{DIGITAL FEATURES}

This article is published with digital features, including a summary slide, to facilitate understanding of the article. To view digital features for this article go to https://doi.org/10.6084/ m9.figshare.13622792.

\section{INTRODUCTION}

Type 2 diabetes (T2D) is a progressive disease requiring long-term management of hyperglycaemia aimed at improving clinical outcomes [1]. Current guidelines recommend achieving glycated haemoglobin (HbA1c) target levels of $6.5-7.0 \%(48-53 \mathrm{mmol} / \mathrm{mol})$ or lower in most patients, provided that these targets are reached with medications associated with a very low risk of hypoglycaemia. Less stringent targets $(<8 \%$; $64 \mathrm{mmol} / \mathrm{mol}$ ) are suggested for patients with a history of severe hypoglycaemia, limited life expectancy, advanced micro- or macrovascular complications, comorbidities or long-standing diabetes [2, 3]. To reach HbA1c target levels, guidelines recommend using the sequential addition of second-line glucose-lowering agents to ongoing metformin therapy [2]. When individualized HbA1c targets are not achieved, and in the presence of clear signs of insulin deficiency, one of the intensification strategies is the initiation of basal insulin supported oral therapy (BOT) [4].

Despite these recommendations, glycaemic control remains suboptimal in a high proportion of T2D patients, including those who have started insulin treatment. Observational Italian data indicate that 2 years after starting insulin therapy, HbA1c values were still $>8 \%$ in almost $50 \%$ of patients surveyed [5]. This result is consistent with data from a large observational 
study showing that only $28 \%$ of European and US insulin-naïve T2D patients had achieved HbA1c levels $\leq 7 \%$ (53 mmol/mol) 24 months after basal insulin (BI) initiation [6].

These observations clearly suggest a clinical inertia in BI therapy uptitration and/or intensification. In a cohort study evaluating data of 11,696 patients from UK Clinical Practice Research Datalink database, fewer than one third of BOT patients eligible for treatment intensification had their treatment regimen intensified, and the median time to intensification was 3.7 years [7].

BOT can be intensified by combining BI with rapid-acting insulin or by adding a glucagonlike peptide-1 receptor agonist (GLP-1RA) in a loose- or fixed-ratio combination. The addition of a GLP-1RA to ongoing BI therapy has consistently been shown to improve HbA1c and postprandial glucose (PPG) excursions and represents a useful alternative to uptitrating BI or starting a basal-bolus regimen [8]. Clinical trials have shown that this strategy, compared to basal-bolus regimens, allows equal or better glycaemic control with lower risk of hypoglycaemia, has a beneficial effect on body weight and results in a reduction in total daily insulin dose [9-13]. Furthermore, in this population of patients, GLP-1RA can reduce the risk of adverse cardiovascular outcomes [14].

The use of fixed-dose formulations entails a single daily injection, thus reducing the complexity of the therapeutic regimen and increasing treatment adherence. The slower titration of the GLP-1RA dose resulting from the use of these formulations reduces the occurrence of gastrointestinal adverse events and contributes to better treatment adherence and persistence $[15,16]$. To date, two fixed-ratio combinations are available: IDegLira (insulin degludec and liraglutide) and iGlarLixi (insulin glargine and lixisenatide).

In this study, we used the Delphi method to elaborate a consensus among a panel of Italian diabetes specialists on treatment intensification strategies in patients with T2D failing BOT. The panel specifically focused on treatment intensification strategies involving the use of $\mathrm{BI}$ and GLP-1RA in combination.

\section{METHODS}

The Delphi method is a structured technique aimed at obtaining, by repeated rounds of questionnaires, a consensus opinion from a panel of experts in areas where evidence is scarce and opinion is important [17-19]. In the present study, the consensus process consisted of a two-step Delphi method, which took place between February and June 2020.

The online survey was developed by a panel of six physicians, all experts in diabetes management, identified here as key opinion leaders (KOLs) in the field of T2D in Italy. The KOLs identified ten statements involving a total of 77 items which were in serious need of clarification and debate, all focused on topics of BOT: BOT definition, BOT failure definition, insulin intensification strategies, fixed-dose combinations and fixed-dose combinations of BI and GLP-1RA (Table 1). Once developed, the survey was evaluated by 12 external validators to test its understandability and clarity, following which the questionnaire was distributed to 84 expert diabetologists via an online survey platform. The panellists were clinicians with solid experience in the field of diabetes, selected throughout the country among members of Diabetes Clinics Medical Staff, so that the whole country was homogeneously represented [18].

Panellists were asked to rate the level of their agreement or disagreement with each item on a 5-point Likert scale, scored as follows: 1, extremely disagree; 2 , disagree; 3 , agree; 4 , mostly agree; and 5, extremely agree. All answers were categorized into two categories: for the purpose of this study, "extremely disagree" and "disagree" were categorized into category "Negative Consensus"; "agree", "mostly agree" and "extremely agree" were categorized into "Positive Consensus". A cutoff of $66 \%$ of agreement/disagreement was chosen a priori to represent positive or negative consensus, respectively. No consensus was reached when $<66 \%$ of the answers fell in the same category $[18,19]$. For the items on which consensus had not been achieved, panellists were asked to rate again in a second round their agreement/disagreement, 
Table 1 List of consensus statements

\begin{tabular}{|c|c|}
\hline Area & Statement/Item \\
\hline BOT definition & $\begin{array}{l}\text { Statement } 1 . \text { In my clinical practice Basal Oral Therapy ... } \\
1.1 \text { includes, in addition to basal insulin, in most cases metformin and/or DPP-4 inhibitors } \\
1.2 \text { does not include a long-acting insulin analogue of the latest generation } \\
1.3 \text { includes, in addition to basal insulin, in most cases metformin and/or sulfonylureas } \\
1.4 \text { includes, in addition to basal insulin, in most cases metformin and/or SGLT2 inhibitors } \\
1.5 \text { is used in most cases in patients with chronic kidney disease }\end{array}$ \\
\hline BOT definition & $\begin{array}{l}\text { Statement 2. I believe that an appropriate Basal Oral Therapy... } \\
2.1 \text { includes, in addition to basal insulin, in most cases metformin and/or SGLT2 inhibitors } \\
2.2 \text { includes, in addition to basal insulin, in most cases metformin and/or sulfonylureas } \\
2.3 \text { is used in most cases in patients with chronic kidney disease } \\
2.4 \text { does not include a long-acting insulin analogue of the latest generation } \\
2.5 \text { includes, in addition to basal insulin, in most cases metformin and/or DPP-4 inhibitors }\end{array}$ \\
\hline BOT failure & $\begin{array}{l}\text { Statement } 3 . \text { I believe that the patient is in Basal Oral Therapy failure if ... } \\
\text { 3.1 has fasting and postprandial blood glucose values above the individualized target according } \\
\text { to patient age and comorbidity } \\
3.2 \text { has HbAlc values above the target } \\
\text { 3.3 has nocturnal hypoglycaemic episodes } \\
\text { 3.4 has fasting blood glucose values in the target and HbAlc values above the target } \\
\text { 3.5 has a marked increase in body weight } \\
\text { 3.6 has fasting blood glucose and HbAlc values in the target and postprandial glycaemic } \\
\text { excursions } \\
\text { 3.7 has fasting blood glucose levels above the target }\end{array}$ \\
\hline BOT failure & $\begin{array}{l}\text { Statement } 4 \text { Critical issues in patients in Basal Oral therapy are: } \\
\text { 4.1 Adherence to therapy } \\
\text { 4.2 Body weight control } \\
4.3 \text { Costs } \\
\text { 4.4 Titration } \\
4.5 \text { Achievement of the individualized glycaemic targets } \\
\text { 4.6 Risk of hypoglycaemia } \\
\text { 4.7 Control of postprandial blood glucose }\end{array}$ \\
\hline Insulin intensification strategies & $\begin{array}{l}\text { Statement } 5 \text { In a patient in Basal Oral Therapy not adequately controlled... } \\
5.1 \text { I change the basal insulin } \\
5.2 \text { I switch to multi-injection insulin therapy } \\
5.3 \text { I titrate basal insulin } \\
5.4 \text { I add another oral agent } \\
5.5 \text { I carry out an educational reinforcement } \\
5.6 \text { I change therapy by adding a GLP-1 receptor agonist } \\
5.7 \text { I change therapy by replacing basal insulin with a fixed ratio association of basal insulin and } \\
\text { GLP-1 receptor agonist } \\
5.8 \text { I search areas of lipodystrophy } \\
5.9 \text { I change therapy by replacing basal insulin with a GLP-1 receptor agonist }\end{array}$ \\
\hline Insulin intensification strategies & $\begin{array}{l}\text { Statement } 6 \text { I believe that the advantages of adding a GLP-1 receptor agonist to basal insulin are: } \\
\text { 6.1 Minimization of undesirable effects } \\
\text { 6.2 Synergy of the mechanisms of action of the individual molecules } \\
\text { 6.3 Control of body weight } \\
\text { 6.4 Cardiovascular protection } \\
\text { 6.5 Protection of kidney function } \\
\text { 6.6 Effective control of fasting and postprandial blood glucose } \\
\text { 6.7 Facilitating patient adherence to injection therapy }\end{array}$ \\
\hline
\end{tabular}


Table 1 continued

\begin{tabular}{|c|c|}
\hline$\overline{\text { Area }}$ & Statement/Item \\
\hline Fixed-dose combinations & $\begin{array}{l}\text { Statement } 7 \text { In my opinion, fixed-dose combinations... } \\
7.1 \text { have a better cost/effectiveness profile } \\
7.2 \text { reduce the risk of mortality and hospitalization } \\
7.3 \text { potentiate side effects of individual molecules } \\
7.4 \text { prevent the optimization of the dosages of individual molecules } \\
7.5 \text { are always an advantage } \\
7.6 \text { help improving compliance and/or adherence } \\
7.7 \text { offer little help compared to a loose dose combination } \\
7.8 \text { maximize effectiveness of individual molecules }\end{array}$ \\
\hline $\begin{array}{l}\text { Fixed-dose combinations of basal } \\
\text { insulin and GLP-1RA }\end{array}$ & $\begin{array}{l}\text { Statement } 8 \text { I believe that the advantages of replacing basal insulin (in a patient in BOT failure) } \\
\text { with a fixed dose combination of basal insulin and GLP-1 receptor agonist are: } \\
\text { 8.1 Control of body weight } \\
\text { 8.2 Efficacy in fasting and postprandial glucose control } \\
\text { 8.3 Protection of kidney function } \\
\text { 8.4 Reduction of insulin dosages } \\
\text { 8.5 Minimization of side effects of individual molecules } \\
\text { 8.6 Maximizing the efficacy of individual molecules } \\
\text { 8.7 Facilitating patient compliance with injection therapy } \\
\text { 8.8 Cost reduction } \\
\text { 8.9 Cardiovascular protection }\end{array}$ \\
\hline $\begin{array}{l}\text { Fixed-dose combinations of basal } \\
\text { insulin and GLP-1RA }\end{array}$ & $\begin{array}{l}\text { Statement } 9 \text { In my clinical practice IDegLira ... } \\
9.1 \text { is considered a strengthened basal insulin } \\
9.2 \text { is an alternative to multi-injection insulin therapy (or basal bolus) } \\
9.3 \text { guarantees cardiovascular protection } \\
9.4 \text { helps achieving therapeutic targets } \\
9.5 \text { is not preferred due to the need to reduce the initial insulin dosage } \\
9.6 \text { limits hypoglycaemia episodes and weight gain } \\
9.7 \text { is not preferred due to the limitations to the titration of the GLP-1 receptor agonist } \\
9.8 \text { is an alternative to the loose dose combination of basal insulin and GLP-1 receptor agonist } \\
9.9 \text { could be considered a useful therapeutic option in the patient with chronic kidney disease } \\
\text { 9.10 reduces the gastrointestinal side effects of the GLP-1 receptor agonist due to the gradual } \\
\text { titration }\end{array}$ \\
\hline $\begin{array}{l}\text { Fixed-dose combinations of basal } \\
\text { insulin and GLP-1RA }\end{array}$ & $\begin{array}{l}\text { Statement } 10 \text { In my clinical practice iGlarLixi ... } \\
10.1 \text { limit hypoglycaemia episodes and weight gain } \\
\text { 10.2 is an alternative to the loose dose combination of basal insulin and GLP-1 receptor } \\
\text { agonist } \\
10.3 \text { helps achieving therapeutic targets } \\
10.4 \text { is an alternative to multi-injection (or basal-bolus) insulin therapy } \\
10.5 \text { is not preferred due to the limitations to the titration of the GLP-1 receptor agonist } \\
\text { 10.6 reduces the gastrointestinal side effects of the GLP-1 receptor agonist due to the gradual } \\
\text { titration } \\
10.7 \text { is considered a strengthened basal insulin } \\
10.8 \text { could be considered a useful therapeutic option in the patient with chronic kidney disease } \\
10.9 \text { guarantees cardiovascular protection } \\
10.10 \text { is not preferred due to the need to reduce the initial insulin dosage }\end{array}$ \\
\hline
\end{tabular}

BOT Basal insulin supported oral therapy, DDP-4 dipeptidyl peptidase-4, GLP-1RA glucagon-like peptide-1 receptor agonist, HbAIc glycated haemoglobin, IDegLira fixed-ratio combination insulin degludec/liraglutide, iGlarLixi fixed-ratio combination insulin glargine/ Pixisenatide, $S G L T 2$ sodium-glucose co-transporter-2 
after being provided with relevant literature on the topic, selected by the KOLs.

Descriptive statistics were used to summarize the results from rounds 1 and 2 .

The study is based on a survey that does not involve the participation of human subjects nor patient data management and does not aim to modify the current clinical practice of participants. Consequently, this study did not require ethical approval.

\section{RESULTS}

In the first round of the Delphi survey, there were 80 respondents among the 84 invited panellists (response rate 95\%). Round 2 was completed by all of the 80 panellists who responded to round 1 . Mean age of the respondents was 48 years and 65\% were female (Table 2). In round 1 , consensus was reached for 62 of the 77 statements $(80.5 \%)$. The second round was performed on the 15 items for which consensus had not been reached, and consensus was reached for nine of these 15 items. Overall, consensus was ultimately reached for 71 items of the Delphi survey (92.2\%), while no consensus was reached for six items (Fig. 1).

Table 3 summarizes the statements and items and presents the percentage agreement for each.

\section{BOT Definition}

The panellists strongly agreed that, in clinical practice, BOT includes in most cases, in addition to BI, metformin and/or a dipeptidyl peptidase-4 (DPP-4) inhibitor (91\%) or an sodiumglucose co-transporter-2 (SGLT2) inhibitor (98\%). Panellists also strongly agreed to define appropriate BOT when metformin and/or SGLT2 inhibitors (99\%) or DPP-4 inhibitors $(93 \%)$ are given in combination with BI. Panellists agreed that the sulfonylureas are not commonly included as an option for their patients in BOT and that these options should not be considered an appropriate BOT strategy (78 and $83 \%$, respectively). A negative consensus was reached on the item stating that in clinical practice BOT does not include a long-
Table 2 Characteristics of responders in the Delphi survey

\begin{tabular}{ll}
\hline Characteristics of responders & Values \\
\hline Gender (female) & $65 \%$ \\
Mean age (years) & $48 \pm 9.82$ \\
Age (years) & \\
$\leq 40$ & $28.8 \%$ \\
$41-50$ & $28.8 \%$ \\
$>50$ & $42.5 \%$ \\
Italian region & \\
Northern Italy & $41.3 \%$ \\
Central Italy & $33.8 \%$ \\
Southern Italy & $25.0 \%$ \\
\hline
\end{tabular}

Values in table are presented as a percentage or as the mean \pm standard deviation,

acting insulin analogue of the latest generation (70\%).

There was no consensus on whether BOT is used preferentially or should be used in patients with chronic kidney disease (CKD).

\section{BOT Failure}

There was clear consensus on the definition of BOT failure; in particular, the panellists strongly agreed that a patient is in BOT failure when fasting plasma glucose (FPG), PPG and/or HbA1c levels are above the individualized targets (96\%). Furthermore, panellists reached a consensus in defining BOT failure if nocturnal hypoglycaemic episodes are experienced (73\%) or if there is a marked increase in body weight (70\%).

There was consensus that all of the following aspects are critical in BOT: control of PPG (89\%); achievement of the individualized glycaemic targets $(82 \%)$; risk of hypoglycaemia (77\%); body weight control (76\%); insulin titration (75\%); and adherence to therapy (70\%). Costs of BOT were not considered to be a critical issue $(71 \%)$. 


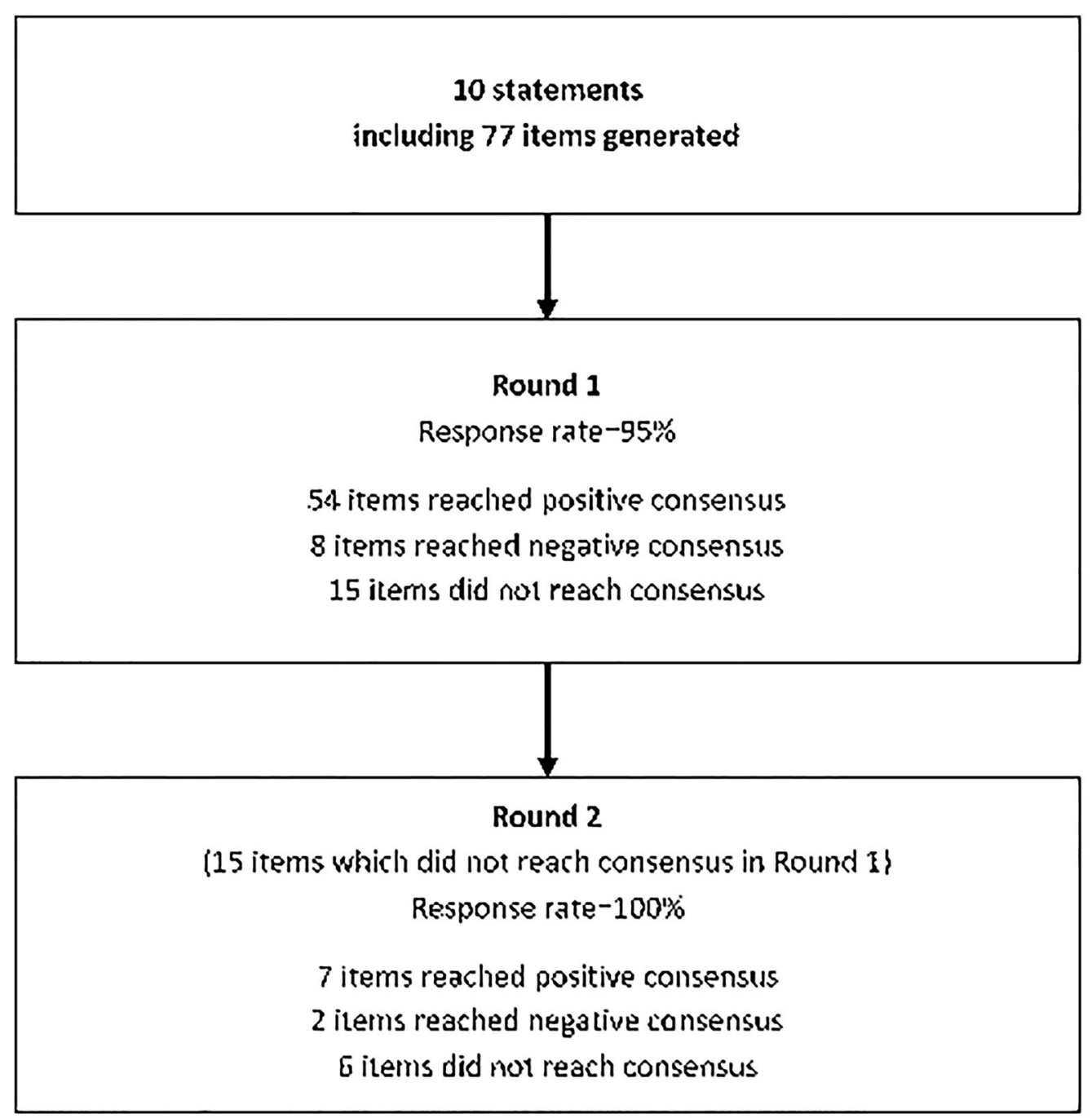

Fig. 1 Delphi survey flowchart

\section{Insulin Intensification Strategies}

Panellists strongly agreed on the strategies to adopt when BOT fails in a patient. The following therapeutic strategies were supported by the panellists, with agreement ranging between 95 and 99\%: replacing BI with a fixed-dose combination of BI/GLP-1RA; adding a GLP-1RA to BI ongoing therapy; uptitrating insulin doses; providing educational reinforcement; and searching for areas of lipodystrophy. Consensus was also reached that the addition of another oral agent $(81 \%)$ or a change of BI $(75 \%)$ could be useful. Finally, agreement was reached on the replacement of BI with a GLP-1RA (69\%) or the switch to multi-injection insulin therapy (68\%).

Consensus on the advantages of adding GLP1RA to ongoing BI therapy was almost unanimous. Panellists were in complete agreement that the advantage of the combination therapy is derived from the synergy of the mechanisms of action of the individual molecules, with an efficacy on both FPG and PPG, thereby providing both cardiovascular and kidney protection, and a positive effect on body weight. Furthermore, consensus was reached that the 
Table 3 Results of the Delphi survey

\section{Statement}

\section{Consensus score}

Disagreement

(score 1-2) (\%)

Agreement (score

3-5) (\%)

Statement 1. In my clinical practice Basal Oral Therapy ...

1.1 includes, in addition to basal insulin, in most cases metformin and/or

DPP-4 inhibitors

1.2 does not include a long-acting insulin analogue of the latest generation

1.3 includes, in addition to basal insulin, in most cases metformin and/or 78 sulfonylureas

1.4 includes, in addition to basal insulin, in most cases metformin and/or 3

SGLT2 inhibitors

1.5 is used in most cases in patients with chronic kidney disease

Statement 2. I believe that an appropriate Basal Oral Therapy...

2.1 includes, in addition to basal insulin, in most cases metformin and/or

SGLT2 inhibitors

2.2 includes, in addition to basal insulin, in most cases metformin and/or sulfonylureas

2.3 is used in most cases in patients with chronic kidney disease

2.4 does not include a long-acting insulin analogue of the latest generation

2.5 includes, in addition to basal insulin, in most cases metformin and/or

DPP-4 inhibitors

Statement 3. I believe that the patient is in Basal Oral Therapy failure if ......

3.1 has fasting and postprandial blood glucose values above the individualized 4 target according to patient age and comorbidity

3.2 has HbAlc values above the target

3.3 has nocturnal hypoglycaemic episodes

3.4 has fasting blood glucose values in the target and $\mathrm{HbAlc}$ values above the 20 target

3.5 has a marked increase in body weight

3.6 has fasting blood glucose and HbAlc values in the target and postprandial 31 glycaemic excursions

3.7 has fasting blood glucose levels above the target

Statement 4 Critical issues in patients in Basal Oral therapy are:

4.1 Adherence to therapy

30

70

4.2 Body weight control

4.3 Costs

71 
Table 3 continued

\begin{tabular}{|c|c|c|}
\hline \multirow[t]{2}{*}{ Statement } & \multicolumn{2}{|l|}{ Consensus score } \\
\hline & $\begin{array}{l}\text { Disagreement } \\
(\text { score } 1-2)(\%)\end{array}$ & $\begin{array}{l}\text { Agreement (score } \\
3-5)(\%)\end{array}$ \\
\hline 4.4 Titration & 25 & 75 \\
\hline 4.5 Achievement of the individualized glycaemic targets & 18 & 82 \\
\hline 4.6 Risk of hypoglycaemia & 24 & 77 \\
\hline 4.7 Control of postprandial blood glucose & 11 & 89 \\
\hline \multicolumn{3}{|l|}{ Statement 5 In a patient in Basal Oral Therapy not adequately controlled... } \\
\hline 5.1 I change the basal insulin & 25 & 75 \\
\hline 5.2 I switch to multi-injection insulin therapy & 33 & 68 \\
\hline 5.3 I titrate basal insulin & 4 & 96 \\
\hline 5.4 I add another oral agent & 19 & 81 \\
\hline 5.5 I carry out an educational reinforcement & 3 & 98 \\
\hline 5.6 I change therapy by adding a GLP-1 receptor agonist & 3 & 98 \\
\hline $\begin{array}{l}5.7 \text { I change therapy by replacing basal insulin with a fixed ratio association of } \\
\text { basal insulin and GLP-1 receptor agonist }\end{array}$ & 1 & 99 \\
\hline 5.8 I search areas of lipodystrophy & 5 & 95 \\
\hline 5.9 I change therapy by replacing basal insulin with a GLP-1 receptor agonist & 31 & 69 \\
\hline \multicolumn{3}{|c|}{ Statement 6 I believe that the advantages of adding a GLP-1 receptor agonist to basal insulin are: } \\
\hline 6.1 Minimization of undesirable effects & 18 & 83 \\
\hline 6.2 Synergy of the mechanisms of action of the individual molecules & 0 & 100 \\
\hline 6.3 Control of body weight & 0 & 100 \\
\hline 6.4 Cardiovascular protection & 0 & 100 \\
\hline 6.5 Protection of kidney function & 1 & 99 \\
\hline 6.6 Effective control of fasting and postprandial blood glucose & 1 & 99 \\
\hline 6.7 Facilitating patient adherence to injection therapy & 5 & 95 \\
\hline \multicolumn{3}{|l|}{ Statement 7 In my opinion, fixed-dose combinations... } \\
\hline 7.1 have a better cost/effectiveness profile & 13 & 88 \\
\hline 7.2 reduce the risk of mortality and hospitalization & 15 & 85 \\
\hline 7.3 potentiate side effects of individual molecules & 70 & 30 \\
\hline 7.4 prevent the optimization of the dosages of individual molecules & 49 & 51 \\
\hline 7.5 are always an advantage & 46 & 54 \\
\hline 7.6 help improving compliance and/or adherence & 1 & 99 \\
\hline 7.7 offer little help compared to a loose dose combination & 85 & 15 \\
\hline
\end{tabular}


Table 3 continued

Statement

Consensus score

\begin{tabular}{ll}
\hline $\begin{array}{l}\text { Disagreement } \\
\text { (score } 1-2)(\%)\end{array}$ & $\begin{array}{l}\text { Agreement (score } \\
3-5)(\%)\end{array}$ \\
\hline
\end{tabular}

7.8 maximize effectiveness of individual molecules

20

80

Statement 8 I believe that the advantages of replacing basal insulin (in a patient in BOT failure) with a fixed dose combination of basal insulin and GLP-1 receptor agonist are:

8.1 Control of body weight $\quad 1 \quad 99$

8.2 Efficacy in fasting and postprandial glucose control $\quad 1 \quad 99$

$\begin{array}{lll}8.3 \text { Protection of kidney function } & 3 & 98\end{array}$

$\begin{array}{lll}8.4 \text { Reduction of insulin dosages } & 4 & 96\end{array}$

8.5 Minimization of side effects of individual molecules $\quad 8 \quad 93$

8.6 Maximizing the efficacy of individual molecules $\quad 14 \quad 86$

8.7 Facilitating patient compliance with injection therapy $\quad 1 \quad 99$

8.8 Cost reduction $\quad 15 \quad 85$

8.9 Cardiovascular protection $\quad 1 \quad 99$

Statement 9 In my clinical practice IDegLira ...

9.1 is considered a strengthened basal insulin $\quad 20 \quad 80$

9.2 is an alternative to multi-injection insulin therapy (or basal bolus) $\quad 11 \quad 89$

9.3 guarantees cardiovascular protection $\quad 5 \quad 95$

$\begin{array}{lll}9.4 \text { helps achieving therapeutic targets } & 0 & 100\end{array}$

9.5 is not preferred due to the need to reduce the initial insulin dosage $\quad 79 \quad 21$

9.6 limits hypoglycaemia episodes and weight gain $\quad 0 \quad 100$

9.7 is not preferred due to the limitations to the titration of the GLP-1 $\quad 79 \quad 21$

receptor agonist

9.8 is an alternative to the loose dose combination of basal insulin and GLP-1 $21 \quad 79$

receptor agonist

9.9 could be considered a useful therapeutic option in the patient with 0

100

chronic kidney disease

9.10 reduces the gastrointestinal side effects of the GLP-1 receptor agonist due 3

98

to the gradual titration

Statement 10 In my clinical practice iGlarLixi ...

10.1 limit hypoglycaemia episodes and weight gain $\quad 10$

$10 \quad 90$

10.2 is an alternative to the loose dose combination of basal insulin and GLP- $18 \quad 83$

1 receptor agonist

10.3 helps achieving therapeutic targets

14

86 
Table 3 continued

\begin{tabular}{|c|c|c|}
\hline \multirow[t]{2}{*}{ Statement } & \multicolumn{2}{|l|}{ Consensus score } \\
\hline & $\begin{array}{l}\text { Disagreement } \\
\text { (score 1-2) (\%) }\end{array}$ & $\begin{array}{l}\text { Agreement (score } \\
3-5)(\%)\end{array}$ \\
\hline 10.4 is an alternative to multi-injection (or basal-bolus) insulin therapy & 24 & 76 \\
\hline $\begin{array}{l}10.5 \text { is not preferred due to the limitations to the titration of the GLP-1 } \\
\text { receptor agonist }\end{array}$ & 58 & 43 \\
\hline $\begin{array}{l}10.6 \text { reduces the gastrointestinal side effects of the GLP- } 1 \text { receptor agonist due } \\
\text { to the gradual titration }\end{array}$ & 16 & 84 \\
\hline 10.7 is considered a strengthened basal insulin & 33 & 68 \\
\hline $\begin{array}{l}10.8 \text { could be considered a useful therapeutic option in the patient with } \\
\text { chronic kidney disease }\end{array}$ & 16 & 84 \\
\hline 10.9 guarantees cardiovascular protection & 51 & 49 \\
\hline 10.10 is not preferred due to the need to reduce the initial insulin dosage & 74 & 26 \\
\hline
\end{tabular}

association leads to enhancement of patient adherence (95\%) and minimization of side effects $(83 \%)$.

\section{Fixed-Dose Combinations}

Panellists strongly agreed that fixed-dose combinations are useful for improving compliance and adherence (99\%) and have a better cost/effectiveness profile $(88 \%)$ than the individual components. There was also consensus on the utility of fixed-dose combinations for reducing the risk of mortality and hospitalization $(85 \%)$ and their capacity to maximize the effectiveness of the individual molecules (80\%). In addition, there was a negative consensus that loose-dose combinations are more useful than fixed-dose ones (85\%) and that fixed-dose combinations can exacerbate side effects of individuals molecules (70\%). However, no consensus was reached on whether fixed-dose combinations preclude optimization of the dosages of the individual components or whether they always have an advantage.

\section{Fixed-Dose Combinations of BI and GLP- 1RA}

There was strong consensus that fixed-dose combinations of BI and GLP-1RA have all of the following benefits: control of body weight (99\%); efficacy in FPG and PPG control (99\%); facilitating patient compliance with injection therapy (99\%); providing cardiovascular (99\%) and kidney protection (98\%); reducing insulin dosages (96\%); minimizing side effects of individual molecules (93\%); maximizing the efficacy of individual molecules (86\%); and reducing costs (85\%).

When the two available fixed-dose combinations were considered, there was consensus that both IDegLira and iGlarLixi are associated with a low risk for hypoglycaemic events and weight increase (100 and 90\%, respectively) and are useful in achieving therapeutic targets (100 and $86 \%$, respectively). Panellists also agreed that IDegLira and iGlarLixi could be considered useful therapeutic options in patients with CKD (100\% and $84 \%$, respectively).

Panellists agreed in considering IDegLira and iGlarLixi as strengthened BIs (80 and 68\%, respectively), as alternatives to multi-injection insulin therapy (89 and 76\%, respectively) or as 
alternatives to loose-dose combinations of $\mathrm{BI}$ and GLP-1RA (79 and 83\%, respectively). There was clear consensus that both fixed-dose combinations help reduce gastrointestinal side effects of the GLP-1RA (98\% for IDegLira and $84 \%$ for iGlarLixi).

Panellists agreed that the need to reduce the initial insulin dosage is not one of the reasons why both fixed-dose combinations are not preferred (79\% for IDegLira and 74\% for iGlarLixi).

Finally, there was a strong consensus on the effectiveness of IDegLira on cardiovascular protection (95\%). No consensus was reached on the cardiovascular protection provided by iGlarLixi.

Panellists disagreed that IDegLira is not preferred due to the limitations to the titration of the GLP-1RA (79\%). The same item, but referring to iGlarLixi, did not reach a consensus among the Expert Panel.

\section{DISCUSSION}

The consensus reached in this Delphi study provides an overview of how diabetes specialists in Italy manage T2D patients whose BOT failed and gives a snapshot of issues that balance indications from guidelines and unmet needs from clinical practice. Consensus was reached on a variety of statements regarding treatment intensification after failure of BOT. Consensus was not reached on six of the 77 items, mainly due to heterogeneity in the management of patients at this disease stage in clinical practice.

DPP-4 inhibitors and SGLT2 inhibitors were the most widely used drugs associated with BI and metformin in clinical practice, while sulfonylureas were considered to be drugs that were no longer used or inappropriate in association with BI, which is in line with guidelines that recommend avoiding the use of sulfonylureas with BI and metformin due to the high risk of hypoglycaemia with this combination $[3,4]$. However, data from the DARWIN T2D study documented that sulfonylureas were still a frequently adopted therapeutic option associated with BI [20].

There is a tendency to prefer newer secondgeneration insulin analogues since long and ultra-long BI analogues have a similar efficacy in terms of glycaemic control as the first-generation insulins, but with a lower risk of hypoglycaemia. The former have a more physiological pharmacokinetics profile that allows flexibility in the administration time [21].

The lack of agreement on the use of BOT in patients with CKD reflects different approaches in the treatment of this patient population, although recommendations do suggest using BI preferably in combination with a DPP-4 inhibitor in the presence of kidney impairment, especially in elderly patients [3]. CKD affects up to $40 \%$ of people with T2D and represents a significant health challenge in terms of management because the majority of glucose-lowering agents must be downtitrated or withdrawn with declining estimated glomerular filtration rate [22]. Therefore, BOT represents a rationale therapy when CKD is present. However, despite the current paucity of data on the use of long-acting BI in patients with T2D and CKD, observational studies have demonstrated that insulin glargine and insulin degludec are effective in reducing $\mathrm{HbA1c}$ with a low risk of hypoglycaemic events [23-25]. In a secondary analysis from the DEVOTE trial, a lower rate of severe hypoglycaemia was observed with degludec compared with insulin glargine, even in the presence of CKD [26]. The lack of consensus in our study could also reflect a progressive change, that is still ongoing, in the management of patients with T2D and CKD.

Reaching an agreement on the definition of BOT failure is a prerequisite to identifying strategies for therapy intensification. The panellists reached consensus to consider BOT failure not only in relation to the inability of the therapy to control the traditional glycaemic indicators (HbA1c, FPG, PPG), but also to the presence of side effects, such as nocturnal hypoglycaemia or weight gain.

Fear of hypoglycaemia is one of the determinants of suboptimal glycaemic control. It can be overcome by using an ultra-long-acting insulin analogue, such as degludec, which has been shown to result in a lower incidence of hypoglycaemia, with a reduction in FPG levels $[27,28]$. Despite this evidence, newer secondgeneration insulins are still not used in a large 
portion of patients treated with $\mathrm{BI}$, and the risk of hypoglycaemia is still an issue.

The association of increase in body weight with BOT failure is still a debated issue. A metaanalysis of cardiovascular outcome trials on glucose-lowering drugs found that a decrease in bodyweight of $1 \mathrm{~kg}$ with glucose-lowering interventions led to a statistically significantly reduction of $5.9 \%$ in the relative risk of heart failure $[29,30]$. Therefore, weight gain is considered to be a crucial aspect, representing an important challenge in the management of patients with T2D on insulin treatment [31].

The consensus that patients with T2D on BOT who experience hypoglycaemia or weight gain should require a change in therapy even if glycemic targets are met is revolutionary. At the present time, combination therapy with BI and GLP-1RA provides the possibility of reaching glycemic control with lower insulin doses, thereby dramatically limiting the risk of hypoglycaemia and without weight gain. This is one of the most important clinical messages from our survey.

Despite a consensus on the critical role of insulin titration in the BOT strategy, a modest titration of $\mathrm{BI}$ in the real-world setting has been observed, contributing to an inadequate glycaemic control [32, 33]. Data from Italian and international studies highlight that more than half of subjects with poorly controlled T2D receive low doses of insulin therapy, confirming a trend towards low insulin titration $[6,34,37]$.

Combination therapies, such as BOT, often increase dosing frequency and the treatment burden in patients with T2D, leading to low adherence. In one study, the insulin adherence rate among people with T2D was found to be low, with one quarter of the patients initiating insulin therapy never refilling their prescription [35]. In another study, one third of patients reported insulin omission/non-adherence at least 1 day in the last month, and the majority of physicians reported that their patients did not take their insulin as prescribed [36].

Although costs were not considered to be a critical issue of BOT, it should be noted that a recent study in Italian setting on the two fixed combinations of BI and GLP-1RA showed that IDegLira was associated with improved clinical outcomes at higher costs relative to iGlarLixi. The higher costs were due to higher acquisition costs although these were partially offset by reduced complication-related treatment costs [37].

The consensus on changing BI therapy is in line with existing evidence when the BI is not an ultra-long-acting insulin analogue. Experimental and observational studies have demonstrated that switching to insulin degludec from other BI improved glycaemic control with a low risk of overall hypoglycaemia, irrespective of previous BI therapy [38, 39]. Even in vulnerable older patients, glargine $300 \mathrm{U} / \mathrm{ml}$ has demonstrated comparable efficacy to glargine $100 \mathrm{U} /$ $\mathrm{ml}$ in terms of $\mathrm{HbA} 1 \mathrm{c}$ reduction, associated with fewer nocturnal hypoglycaemic events [40].

Adding GLP-1RA to ongoing BI therapy has several advantages in terms of synergy of action of the individual molecules: efficacy on metabolic parameters; cardiorenal protection; minimization of side effects; and body weight control. There are several well-documented clinical benefits associated with this combination and it is considered to be a safe and effective treatment intensification option [41-43]. In addition, this therapeutic strategy has been found to reduce the risk of major cardiovascular events, as well as all-cause mortality, hospital admission for heart failure and kidney outcomes [44].

Finally, panellists agreed that the association of insulin and GLP-1RA can improve patient adherence. This aspect is fundamental to successful therapy as adherence is a predictor of metabolic control and diabetes complications [45].

As far as BOT intensification is concerned, it is not surprising that consensus was reached on the switch to multi-injection insulin. This consensus reflects physicians' persistent attitude to initiate multi-injection insulin more often than the combination of BI and GLP-1RA. A metaanalysis evaluating the efficacy of GLP-1RA as add-on to insulin in comparison with basalplus/basal-bolus insulin regimens showed that insulin intensification with GLP-1RA is as effective as multi-injection insulin therapy on achieving the HbA1c target, with the added advantages of significant weight loss, reduced 
risk of hypoglycaemia and sparing of insulin dose [41]. Furthermore, the association has been demonstrated to be less expensive than multiinjection insulin therapy when direct and indirect costs are considered [46, 47].

The lack of agreement for the items on whether fixed-dose combinations preclude optimization of the dosages of the individual components or whether they always have an advantage may depend on the personal clinical experience of the respondent with fixed-dose combinations. The latter do have some advantages, but sometimes lack flexibility in how dosages of the individual components are combined.

A loose-dose combination of BI and GLP-1RA could be chosen if the need for full-dose GLP1RA is prioritized over intensification of the BI dose. It has been demonstrated that, although the loose- and the fixed-dose combinations similarly improved glycaemic control, the loose-dose combination significantly induced a greater body weight reduction than the fixeddose combination, providing the possibility to use higher GLP-1RA doses. However, despite lower GLP-1RA doses, similar metabolic control was obtained due to the titration of insulin doses [48]. Furthermore, the slower titration of GLP-1RA in the fixed-dose combinations, which follows the titration schedule for the BI component, was found to result in less nausea compared with independent titration of GLP1RA [49]. The advantages of the fixed-dose combination come from the synergy of the separate mechanisms of action of BI and GLP1RA, resulting in improved glycaemic control compared with its mono-components given separately, thereby also improving patient compliance. An observational real-life data study reported that patients previously treated with a loose-dose combination of BI and GLP1RA who switched to a fixed-dose combination showed increased adherence with a subsequent improvement in glycaemic control [50].

Results with liraglutide and insulin degludec in the respective cardiovascular outcome trials $[51,52]$ reflect the panellists' opinion: there was, in fact, a strong consensus on the potential effectiveness of IDegLira against cardiovascular events. Despite the lack of direct evidence on the safety and efficacy of IDegLira in the prevention of major cardiovascular events, data on the improvement in cardiovascular risk factors in patients treated with IDegLira compared to BI or basal-bolus are available [53]. The advantageous effects of IDegLira on cardiovascular risk factors are consistent with the results from the LEADER trial, even if the dose of liraglutide administered in the co-formulation IDegLira was lower than the dose of $1.8 \mathrm{mg}$ used in the LEADER trial.

The lack of consensus reached on the cardiovascular protection of iGlarLixi probably resulted from a balance between the attitude of some respondents to consider the beneficial effects of GLP-1RA as a class effect and the findings of the ELIXA trial showing that treatment with lixisenatide, compared to placebo, did not provide protection from major adverse cardiovascular events in patients with $\mathrm{T} 2 \mathrm{D}$ and recent acute coronary syndrome [54]. These results could be misleading as they might be largely influenced by the literature on the individual components rather than the actual experience of the respondents.

Of note, in the light of the different results from cardiovascular outcomes trials with various GLP-1RA, guidelines underline the importance to use, in the intensification algorithm, GLP-1RA with proven cardiovascular benefit [4].

The technical limitation in optimizing the dose of GLP-1RA with the fixed BI/GLP-1RA combination is overcome by the perception of the clinical benefits of the co-formulation; consequently, the unlikelihood of reaching the maximum GLP-1RA dose is not perceived as a limitation. In a European retrospective realworld study, after 6 months of treatment with IDegLira, HbA1c was significantly reduced by $0.9 \%$ in the subgroup of patients on BOT at baseline, with no increase in body weight, and a mean daily dose of IDegLira of 28.5 dose steps (corresponding to $1.03 \mathrm{mg}$ of liraglutide) [55].

No consensus was reached among the Expert Panel on the same item referring to iGlarLixi. The panellists, in fact, believed that the limitations of GLP-1RA titration are not completely overcome by the clinical benefits or by manageability of iGlarLixi. This association offers reduced flexibility in terms of time of 
administration in comparison with IDegLira since the daily dose should be administered within $1 \mathrm{~h}$ before a meal of the day due to the shorter half-life and duration of lixisenatide as compared to liraglutide. Furthermore, the clinical trial programme DUAL, which evaluated the efficacy and safety of IDegLira, is broader than the LIXILAN trials programme developed for the evaluation of iGlarLixi, and investigated multiple clinical situations, including comparisons of IDegLira with different comparators.

To date, no head-to-head studies with the two fixed-dose combinations are available. Indirect comparisons suggest that the efficacy of both co-formulations in terms of reduction of HbA1c is comparable, although iGlarLixi reduces PPG slightly more than IDegLira due to the action of the short-acting GLP-1RA lixisenatide on slowing gastric emptying. On the other hand, IDegLira has a greater effect on the reduction of FPG due to action of the long-acting GLP-1RA liraglutide [56].

There are some limitations to our study. Even when consensus is reached, there is no guarantee it is generalizable; results are dependent on the limited number and the composition of the respondents. However, to minimize the potential for selection bias, panellists were selected based on their experience in the field of diabetes and their distribution thoughout all regions of Italy. Furthermore, the attrition rates over the two rounds were extremely low, ensuring that the range of expert opinion was adequately represented, and the level of consensus was clearly specified a priori.

\section{CONCLUSIONS}

According to this Delphi consensus, failure of BOT is not only defined as not meeting glycemic endpoints, but also by the presence of hypoglycaemia or weight gain. The addition of a GLP-1RA to ongoing BI therapy is clearly identified as the best option to intensify BOT, and the BI/GLP-1RA fixed combinations may increase compliance and optimize the advantages of using these molecules together while providing similar glycemic control.
Some items for which consensus was not reached reflect open questions on which future clinical research will play an important role.

\section{ACKNOWLEDGEMENTS}

The study group includes diabetology experts according to the recommended Delphi procedures.

The contributors to the study group are: Roberto Baratta, Catania; Ilaria Barchetta, Rome; Cristina Bianchi, Pisa; Marco Cianciullo, Salerno; Vincenzo Cimino, Milan; Lorenzo De Candia, Bari; Alessandro Dodesini, Bergamo; Gaetano Leto, Rome; Maria Grazia Magotti, Parma; Roberta Manti, Turin; Carlo Negri, Verona; Francesco Zerella, Benevento; Alberto Giacinto Ambrogio, Milan; Cristiana Baggiore, Florence; Giacomo Bartelloni, Trieste; Laura Bartone, Reggio Calabria; Marzia Bongiovanni, Rome; Francesca Borroni, Civitanova Marche (Macerata); Lucia Brodosi, Bologna; Arianna Busti, Turin; Maria Turchese Caletti, Ravenna; Sergio Cappello, Molfetta (Bari); Diego Carleo, Naples; Francesco Carlino, Maddaloni (Caserta); Angela Carlone, Formia (Latina); Alessandro Cavarape, Udine; Elena Ceccarelli, Siena; Silvestre Cervone, San Marco in Lamis (Foggia); Isabella Colletti, Portogruaro (Venice); Federica D'Angelo, San Benedetto del Tronto (Ascoli Piceno); Pasquale De Cata, Pavia; Loredana De Moliner, Rovereto (Trento); Giuseppe Della Tepa, Naples; Paolo Falasca, Rome; Stefania Fiorini, Bologna; Chiara Foffi, Formia (Latina); Vera Frison, Cittadella (Padua); Alessandra Fusco, Naples; Lorenza Gagliardi, Forlì (ForlìCesena); Chiara Gottardi, Trieste; Lucia Gottardo, Venice; Elena Gramaglia, Turin; Giovanna Gregori, Carrara (Massa e Carrara); Caterina Imbalzano, Reggio Calabria; Vito Antonio Ladiana, Massafra (Taranto); Carlo Lalli, Perugia; Antonio Lanzilli, Naples; Maurizio Latini, Rome; Cristina Lecchi, Sarnico (Bergamo); Patrizia Li Volsi, Pordenone; Filomena Lo Conte, Palo del Colle (Bari); Barbara Macerola, Aielli (L'Aquila); Valeria Maggi, Bari; Sabina Marchetto, Treviso; Giampiero Marino, Pordenone; Stefano Masi, Baiano (Avellino); 
Paola Massucco, Turin; Giuseppe Memoli, Ariano Irpino (Avellino); Viviana Minarelli, Perugia; Marina Miola, Schio (Vicenza); Francesco Mollo, Rovigo; Chiara Moretti, Rome; Giovanni Nasini, Perugia; Elena Nazzari, Savona; Isabella Negro, Saonara (Padua); Vincenzo Nuzzo, Naples; Francesca Paggi, Ancona; Simone Pampanelli, Perugia; Paola Pantanetti, Fermo; Chiara Pascucci, Foligno (Perugia); Bernadetta Pasquino, Merate (Lecco); Massimiliano Petrelli, Ancona; Deamaria Piersanti, Avezzano (L'Aquila); Maria Rosa Pizzo, Sapri (Salerno); Federica Portolan, Cles (Trento); Maria Chiara Quinto, Bari; Mario Ranuzzi, Monterotondo (Rome); Andrea Renzullo, Nola (Naples); Giovanni Ridola, Palermo; Vittoria Romanazzi, Bari; Angela Sabbatini, Aprilia (Latina); Graziano Santantonio, Civitavecchia (Rome); Giovanna Saraceno, Turin; Maurizio Sudano, Urbino (Pesaro e Urbino); Linda Tartaglione, Rome; Camilla Tinari, Milan; Valentina Tommasi, Rome; Anna Maria Veronelli, Milan; Giuseppina Zaltieri, Esine (Brescia); Eva Zanchetta, San Donà di Piave (Venice); Milena Zanon, San Stino di Livenza (Venice); Luca Zenoni, Seriate (Bergamo).

Funding. The journal's Rapid Service Fee was funded by Ethos s.r.l. through a Novo Nordisk S.p.A. unconditional grant. Novo Nordisk S.p.A. did not influence and was not involved in data collection, interpretation, and analysis. No funding or sponsorship was received for this study.

Medical Writing Assistance. Medical writing assistance was provided by Giorgia De Berardis from Ethos srl \& Coresearch. The assistance was funded by Ethos srl \& Coresearch.

Authorship. All named authors meet the International Committee of Medical Journal Editors (ICMJE) criteria for authorship for this manuscript, take responsibility for the integrity of the work as a whole, and have given final approval to the version to be published.

Disclosures. Gianpaolo Fadini received grant support, lecture fees or advisory board fees from Abbott, AstraZeneca, Boehringer Ingelheim, Eli Lilly, Novartis, Novo Nordisk, Sanofi, Genzyme, Servier and Merck Sharp \& Dohme. Olga Disoteo received fees for her role as an advisory board member for Eli Lilly, Boehringer, Astra Zeneca, Sanofi, Novo Nordisk and Takeda; lecture fees from Novo Nordisk; travel support from Astra Zeneca, Novo Nordisk, Sanofi, Eli Lilly, Boehringer and Menarini Diagnostics; consulting fees from Novo Nordisk; and clinical trial support for her institution from Novo Nordisk, Sanofi and Eli Lilly. Riccardo Candido received payments for scientific consultant and educational activities for Eli Lilly, Sanofi Aventis, Takeda, MSD, Astra Zeneca, Novo Nordisk, Roche Diabetes Care, Boehringer Ingelheim, Abbott and Mundipharma Pharmaceuticals. Paolo Di Bartolo has served as a consultant or advisory board member for AstraZeneca, Boehringher Ingelheim, Eli Lily and Company and Novo Nordisk, and has also received honorarium from AstraZeneca, Boehringer Ingelheim, Eli Lilly and Company, Novo Nordisk, Abbott Diagnostic, Mundipharna and Sanofi. Luigi Laviola served in advisory Boards for AstraZeneca, Eli Lilly, Novo Nordisk, Roche Diabetes Care and Sanofi. Agostino Consoli received consultancy or speaker fees from Abbott, AstraZeneca, Boehringer-Ingelheim, Bruno Farmaceutici, Janssen, Eli-Lilly, Merck Sharp \& Dohme, Novartis, NovoNordisk, Roche, SanofiAventis, Servier and Takeda, and has also received research grants from Eli-Lilly and NovoNordisk. All authors received honoraria for the advisory board leading to the present manuscript.

Compliance with Ethics Guidelines. The study is based on a survey that does not involve the participation of human subjects nor patient data management and does not aim to modify the current clinical practice of participants. Consequently, this study did not require ethical approval.

Data Availability. All data generated or analyzed during this study are included in this published article. 
Open Access. This article is licensed under a Creative Commons Attribution-NonCommercial 4.0 International License, which permits any non-commercial use, sharing, adaptation, distribution and reproduction in any medium or format, as long as you give appropriate credit to the original author(s) and the source, provide a link to the Creative Commons licence, and indicate if changes were made. The images or other third party material in this article are included in the article's Creative Commons licence, unless indicated otherwise in a credit line to the material. If material is not included in the article's Creative Commons licence and your intended use is not permitted by statutory regulation or exceeds the permitted use, you will need to obtain permission directly from the copyright holder. To view a copy of this licence, visit http://creativecommons.org/licenses/by$\mathrm{nc} / 4.0 /$.

\section{REFERENCES}

1. Holman RR, Paul SK, Bethel MA, et al. 10-year follow-up of intensive glucose control in type 2 diabetes. N Engl J Med. 2018;359(15):1577-89. https:// doi.org/10.1056/NEJMoa0806470.

2. American Diabetes Association. 6. Glycemic targets: standards of medical care in diabetes-2020. Diabetes Care. 2020;43(Suppl 1):S66-76. https://doi. org/10.2337/dc20-S006.

3. Associazione Medici Diabetologi (AMD)-Società Italiana di Diabetologia (SID). Standard Italiani per la cura del diabete mellito 2018. (In Italian). https:// aemmedi.it/wp-content/uploads/2009/06/AMDStandard-unico1.pdf. Accessed 10 Nov 2020.

4. Davies MJ, D'Alessio DA, Fradkin J, et al. Management of hyperglycemia in type 2 diabetes, 2018. A consensus report by the American Diabetes Association (ADA) and the European Association for the Study of Diabetes (EASD). Diabetes Care. 2018;41(12):2669-701. https://doi.org/10.2337/ dci18-0033.

5. Associazione Medici Diabetologi (AMD). Avvio della terapia insulinica dal 2005 al 2011: Approcci prescrittivi e outcome dell'assistenza. (In Italian) https://aemmedi.it/files/ANNALI-AMD/2014/2014_ Mono_terapia-insulinica_2005-2011.pdf. Accessed 10 Nov 2020.
6. Mauricio D, Meneghini L, Seufert J, et al. Glycaemic control and hypoglycaemia burden in patients with type 2 diabetes initiating basal insulin in Europe and the USA. Diabetes Obes Metab. 2017;19(8): 1155-64. https://doi.org/10.1111/dom.12927.

7. Khunti K, Nikolajsen A, Thorsted BL, et al. Clinical inertia with regard to intensifying therapy in people with type 2 diabetes treated with basal insulin. Diabetes Obes Metab. 2016;18(4):401-9. https:// doi.org/10.1111/dom.12626.

8. Freemantle N, Mamdani M, Vilsbøll T, et al. IDegLira versus alternative intensification strategies in patients with type 2 diabetes inadequately controlled on basal insulin therapy. Diabetes Ther. 2015;6(4):573-91. https://doi.org/10.1007/s13300015-0142-y.

9. Diamant M, Nauck MA, Shaginian R, et al. Glucagon-like peptide 1 receptor agonist or bolus insulin with optimized basal insulin in type 2 diabetes. Diabetes Care. 2014;37(10):2763-73. https://doi. org/10.2337/dc14-0876.

10. Billings LK, Doshi A, Gouet D, et al. Efficacy and safety of IDegLira versus basal-bolus insulin therapy in patients with type 2 diabetes uncontrolled on metformin and basal insulin: the DUAL VII randomized clinical trial. Diabetes Care. 2018;41(5): 1009-16. https://doi.org/10.2337/dc17-1114.

11. Mathieu C, Rodbard HW, Cariou B, et al. A comparison of adding liraglutide versus a single daily dose of insulin aspart to insulin degludec in subjects with type 2 diabetes (BEGIN: VICTOZA ADDON). Diabetes Obes Metab. 2014;16(7):636-44. https://doi.org/10.1111/dom.12262.

12. Rosenstock J, Guerci B, Hanefeld M, et al. GetGoal Duo-2 Trial Investigators. Prandial options to advance basal insulin glargine therapy: testing lixisenatide plus basal insulin versus insulin glulisine either as basal-plus or basal-bolus in type 2 diabetes: the GetGoal Duo-2 trial. Diabetes Care. 2016;39(8):1318-28. https://doi.org/10.2337/dc160014.

13. Tabák ÁG, Anderson J, Aschner P, et al. Efficacy and safety of iGlarLixi, fixed-ratio combination of insulin glargine and lixisenatide, compared with basal-bolus regimen in patients with type 2 diabetes: propensity score matched analysis. Diabetes Ther. 2020;11(1):305-18. https://doi.org/10.1007/ s13300-019-00735-7.

14. Tack CJ, Jacob S, Desouza C, et al. Long-term efficacy and safety of combined insulin and glucagonlike peptide- 1 therapy: evidence from the LEADER trial. Diabetes Obes Metab. 2019;21(11):2450-8. https://doi.org/10.1111/dom.13826. 
15. Gough SC, Bode BW, Woo VC, et al. One-year efficacy and safety of a fixed combination of insulin degludec and liraglutide in patients with type 2 diabetes: results of a 26-week extension to a 26-week main trial. Diabetes Obes Metab. 2015;17(10):965-73. https://doi.org/10.1111/dom. 12498.

16. Rosenstock J, Aronson R, Grunberger G, et al. Benefits of LixiLan, a titratable fixed-ratio combination of insulin glargine plus lixisenatide, versus insulin glargine and lixisenatide monocomponents in type 2 diabetes inadequately controlled on oral agents: the LixiLan-O randomized trial. Diabetes Care. 2016;39(11):2026-35. https://doi.org/10.2337/ dc16-0917. Erratum in: Diabetes Care. 2017;40(6): 809.

17. Hasson F, Keeney S, McKenna H. Research guidelines for the Delphi survey technique. J Adv Nurs. 2000;32(4):1008-15.

18. Giannarou L, Zervas E. Using Delphi technique to build consensus in practice. Int J Bus Sci Appl Manag. 2014;9:65-82.

19. Walker A, Selfe J. The Delphi method: a useful tool for the allied health researcher. Br J Ther Rehabil. 1996;3:677-81.

20. Fadini GP, Bottigliengo D, D'Angelo F, et al.. Comparative effectiveness of DPP-4 inhibitors versus sulfonylurea for the treatment of type 2 diabetes in routine clinical practice: a retrospective multicenter real-world study. Diabetes Ther. 2018;9(4): 1477-90. https://doi.org/10.1007/s13300-0180452-y.

21. Aschner P. Insulin therapy in type 2 diabetes. Am J Ther. 2020;27(1):e79-90. https://doi.org/10.1097/ MJT.0000000000001088.

22. Davies M, Chatterjee S, Khunti K. The treatment of type 2 diabetes in the presence of renal impairment: what we should know about newer therapies. Clin Pharmacol. 2016;8:61-81. https://doi.org/10.2147/ CPAA.S82008.

23. Majumder A, RoyChaudhuri S, Sanyal D. A retrospective observational study of insulin glargine in type 2 diabetic patients with advanced chronic kidney disease. Cureus. 2019;11(11):e6191. https:// doi.org/10.7759/cureus.6191.

24. Garcia de Lucas MD, Olalla Sierra J, Aviles Bueno B. Degludec is effective and safe in real-life treatment for patients with type 2 diabetes mellitus and chronic kidney disease stage 3B. Int J Clin Pract. 2018;72(6):e13098. https://doi.org/10.1111/ijcp. 13098 .
25. Dolores García de Lucas M, Avilés Bueno B, Rivas Ruiz F, Olalla Sierra J. Insulin degludec allows for better glycaemic control with a lower risk of hypoglycaemia in patients with chronic kidney disease and type 2 diabetes. Diabetes Res Clin Pract. 2020;162:108094. diabres.2020.108094. https://doi.org/10.1016/j.

26. Amod A, Buse JB, McGuire DK, et al.. Glomerular filtration rate and associated risks of cardiovascular events, mortality, and severe hypoglycemia in patients with type 2 diabetes: secondary analysis (DEVOTE 11). Diabetes Ther. 2020;11(1):53-70. https://doi.org/10.1007/s13300-019-00715-x.

27. Russell-Jones D, Gall MA, Niemeyer M, et al. Insulin degludec results in lower rates of nocturnal hypoglycaemia and fasting plasma glucose vs. insulin glargine: a meta-analysis of seven clinical trials. Nutr Metab Cardiovasc Dis. 2015;25(10):898-905. https://doi.org/10.1016/j.numecd.2015.06.005.

28. Zhou W, Tao J, Zhou X, Chen H. Insulin degludec, a novel ultra-long-acting basal insulin versus insulin glargine for the management of type 2 diabetes: a systematic review and meta-analysis. Diabetes Ther. 2019;10(3):835-52. s13300-019-0624-4.

https://doi.org/10.1007/

29. Ghosh-Swaby OR, Goodman SG, Leiter LA, et al. Glucose-lowering drugs or strategies, atherosclerotic cardiovascular events, and heart failure in people with or at risk of type 2 diabetes: an updated systematic review and meta-analysis of randomised cardiovascular outcome trials. Lancet Diabetes Endocrinol. 2020;8(5):418-35. https://doi.org/10. 1016/S2213-8587(20)30038-3.

30. Avogaro A, Fadini GP. Cardiovascular and heart failure outcomes with type 2 diabetes therapies: how important is weight loss? Lancet Diabetes Endocrinol. 2020;8(5):353-5. https://doi.org/10. $1016 /$ S2213-8587(20)30044-9.

31. Perreault L, Vincent L, Neumiller JJ, SantosCavaiola T. Initiation and titration of basal insulin in primary care: barriers and practical solutions. J Am Board Fam Med. 2019;32(3):431-47. https:// doi.org/10.3122/jabfm.2019.03.180162.

32. Russell-Jones D, Pouwer F, Khunti K. Identification of barriers to insulin therapy and approaches to overcoming them. Diabetes Obes Metab. 2018;20(3):488-96. https://doi.org/10.1111/dom. 13132.

33. Meneghini LF, Mauricio D, Orsi E, et al. The Diabetes Unmet Need with Basal Insulin Evaluation (DUNE) study in type 2 diabetes: achieving HbA1c targets with basal insulin in a real-world setting. Diabetes Obes Metab. 2019;21(6):1429-36. https:// doi.org/10.1111/dom.13673. 
34. Caputo S, Andersen H, Kaiser M, et al. Effect of baseline glycosylated hemoglobin A1c on glycemic control and diabetes management following initiation of once-daily insulin detemir in real-life clinical practice. Endocr Pract. 2013;19(3):462-70. https://doi.org/10.4158/EP12269.OR.

35. Cramer JA. A systematic review of adherence with medications for diabetes. Diabetes Care. 2004;27(5): 1218-24. https://doi.org/10.2337/diacare.27.5. 1218.

36. Peyrot $M$, Barnett AH, Meneghini LF, SchummDraeger PM. Insulin adherence behaviours and barriers in the multinational global attitudes of patients and physicians in insulin therapy study. Diabet Med. 2012;29(5):682-9. https://doi.org/10. 1111/j.1464-5491.2012.03605.x.

37. Pöhlmann J, Montagnoli R, Lastoria G, et al. Value for money in the treatment of patients with type 2 diabetes mellitus: assessing the long-term cost-effectiveness of IDegLira versus iGlarLixi in Italy. Clinicoecon Outcomes Res. 2019;7(11):605-14. https://doi.org/10.2147/CEOR.S218746.

38. Wysham C, Bhargava A, Chaykin L, et al. Effect of insulin degludec vs insulin glargine U100 on hypoglycemia in patients with type 2 diabetes: the SWITCH 2 randomized clinical trial. JAMA. 2017;318(1):45-56. https://doi.org/10.1001/jama. 2017.7117.

39. Knudsen ST, Lapolla A, Schultes B, et al. Clinical benefits of switching to insulin degludec irrespective of previous basal insulin therapy in people with Type 1 or Type 2 diabetes: evidence from a European, multicentre, retrospective, non-interventional study (EU-TREAT). Diabet Med. 2019;36(7): 868-77. https://doi.org/10.1111/dme.13976.

40. Yale JF, Aroda VR, Charbonnel B, et al. Glycaemic control and hypoglycaemia risk with insulin glargine $300 \mathrm{U} / \mathrm{mL}$ versus glargine $100 \mathrm{U} / \mathrm{mL}$ : a patientlevel meta-analysis examining older and younger adults with type 2 diabetes. Diabetes Metab. 2020;46(2):110-8. https://doi.org/10.1016/j.diabet. 2018.10.002.

41. Castellana M, Cignarelli A, Brescia F, et al. GLP-1 receptor agonist added to insulin versus basal-plus or basal-bolus insulin therapy in type 2 diabetes: a systematic review and meta-analysis. Diabetes Metab Res Rev. 2019;35(1):e3082. https://doi.org/ 10.1002/dmrr.3082.

42. Goldenberg RM, Berard L. Adding prandial GLP-1 receptor agonists to basal insulin: a promising option for type 2 diabetes therapy. Curr Med Res Opin. 2018;34(1):1-10. https://doi.org/10.1080/ 03007995.2017 .1372118$.
43. Trautmann ME, Vora J. Use of glucagon-like peptide-1 receptor agonists among individuals on basal insulin requiring treatment intensification. Diabet Med. 2018;35(6):694-706. https://doi.org/10.1111/ dme.13610.

44. Kristensen SL, Rørth R, Jhund PS, et al. Cardiovascular, mortality, and kidney outcomes with GLP-1 receptor agonists in patients with type 2 diabetes: a systematic review and meta-analysis of cardiovascular outcome trials. Lancet Diabetes Endocrinol. 2019;7(10):776-85. https://doi.org/10.1016/S22138587(19)30249-9. Erratum in: Lancet Diabetes Endocrinol. 2020;8(3):e2.

45. Egede LE, Gebregziabher M, Echols C, Lynch CP. Longitudinal effects of medication nonadherence on glycemic control. Ann Pharmacother. 2014;48(5):562-70. https://doi.org/10.1177/ 1060028014526362.

46. Torre E, Bruno GM, Di Matteo S, et al. Cost-minimization analysis of degludec/liraglutide versus glargine/aspart: economic implications of the DUAL VII study outcomes. Clinicoecon Outcomes Res. 2018;10:413-21. https://doi.org/10.2147/ CEOR.S169045.

47. Afonso M, Ryan F, Pitcher A, Lew E. Evaluating drug cost per responder and number needed to treat associated with lixisenatide on top of glargine when compared to rapid-acting insulin intensification regimens on top of glargine, in patients with type 2 diabetes in the UK, Italy, and Spain. J Med Econ. 2017;20(6):633-9. 13696998.2017.1304395.

48. Morieri ML, Rigato M, Frison V, et al. Fixed versus flexible combination of GLP-1 receptor agonists with basal insulin in type 2 diabetes: a retrospective multicentre comparative effectiveness study. Diabetes Obes Metab. 2019;21(11):2542-52. https:// doi.org/10.1111/dom.13840.

49. Gough SC, Bode B, Woo V, et al. Efficacy and safety of a fixed-ratio combination of insulin degludec and liraglutide (IDegLira) compared with its components given alone: results of a phase 3, open-label, randomised, 26-week, treat-to-target trial in insulin-naive patients with type 2 diabetes. Lancet Diabetes Endocrinol. 2014;2(11):885-93. https:// doi.org/10.1016/S2213-8587(14)70174-3.

50. Melzer-Cohen C, Chodick G, Naftelberg S, et al. Metabolic control and adherence to therapy in type 2 diabetes mellitus patients using IDegLira in a realworld setting. Diabetes Ther. 2020;11(1):185-96. https://doi.org/10.1007/s13300-019-00725-9.

51. Marso SP, Daniels GH, Brown-Frandsen K, et al. Liraglutide and cardiovascular outcomes in type 2 
diabetes. N Engl J Med. 2016;375(4):311-22. https://doi.org/10.1056/NEJMoa1603827.

52. Marso SP, McGuire DK, Zinman B, et al. Efficacy and safety of degludec versus glargine in type 2 diabetes. N Engl J Med. 2017;377(8):723-32. https://doi.org/10.1056/NEJMoa1615692.

53. Vilsbøll T, Blevins TC, Jodar E, et al. Fixed-ratio combination of insulin degludec and liraglutide (IDegLira) improves cardiovascular risk markers in patients with type 2 diabetes uncontrolled on basal insulin. Diabetes Obes Metab. 2019;21(6):1506-12. https://doi.org/10.1111/dom.13675.

54. Pfeffer MA, Claggett B, Diaz R, et al. Lixisenatide in patients with type 2 diabetes and acute coronary syndrome. N Engl J Med. 2015;373(23):2247-57. https://doi.org/10.1056/NEJMoa1509225.

55. Price $H$, Blüher $M$, Prager $R$, et al. Use and effectiveness of a fixed-ratio combination of insulin degludec/liraglutide (IDegLira) in a real-world population with type 2 diabetes: results from a European, multicentre, retrospective chart review study. Diabetes Obes Metab. 2018;20(4):954-962. https://doi.org/10.1111/dom.13182.

56. Perreault L, Rodbard H, Valentine V, Johnson E. Optimizing fixed-ratio combination therapy in type 2 diabetes. Adv Ther. 2019;36(2):265-77. https:// doi.org/10.1007/s12325-018-0868-9. 